\title{
The Isolation of fumB Mutants of Escherichia coli
}

\author{
By JOAN M. HENSON, * NANCY K. BLAKE AND LYNN E. MAREK \\ Department of Microbiology, Montana State University, Bozeman, Montana 59715, USA
}

(Received 13 February 1987; revised 18 April 1987)

\begin{abstract}
Escherichia coli strains lacking the terminus region of the chromosome (min 29-36) due to an IS10-promoted deletion did not grow well in rich medium; they also did not grow on fumarate minimal medium because fum $A C(\min 35.7)$ is deleted. Strains with secondary mutations that partially suppress the deletion phenotype displayed healthier growth on rich medium and grew on minimal fumarate medium. These suppressor mutants had an IS10 insertion just upstream of the fumB structural gene (min 93.4). A strain with a Tnlo insertion at this location was constructed and used to delete nonessential fumB; fumB deletion mutants grew well on both rich and minimal fumarate media.
\end{abstract}

\section{INTRODUCTION}

In a previous study, Escherichia coli strains with large terminus region deletions were isolated (Henson \& Kuempel, 1985). One mutant, strain PLK1608, lacked 7 min of terminus region DNA (min 29-36). The deletion event was promoted by IS10 and the deletion strain had at least one remaining IS 10 in its genome. This strain had a number of unusual properties; it formed many filamentous cells and lacked DNA termination blocks that are present in wild-type strains. In addition, the strain grew poorly on complex medium and not at all on minimal fumarate medium. These growth deficiencies were at least partially attributed to deletion of fum $A C$ (min 35.7), because Guest \& Roberts (1983) found that fumA point mutants also grow poorly on rich medium and do not grow aerobically on fumarate minimal medium. It was also reported (Guest \& Roberts, 1983; Guest et al., 1985) that fumA point mutations could be complemented by fumB (min 93.7) if fumB were present in high copy, such as on a multicopy vector.

We describe here the isolation of strains with insertion mutations that suppress the Fumphenotype of large terminus region deletion strains.

\section{METHODS}

Strains and media. Escherichia coli K12 strains used in this study are listed in Table 1. Bacteria were grown on LB (complex) or M9 (minimal) media (Miller, 1972) at $37^{\circ} \mathrm{C}$. M9 medium supplemented with $1.0 \%$ (w/v) fumarate instead of glucose was used to score strains for fum $A$ and fumB. Tetracycline resistant strains $\left(\mathrm{Tc}^{\mathrm{r}}\right)$ were selected and scored on LB medium containing $20 \mu \mathrm{g}$ tetracycline $\mathrm{ml}^{-1}$, whereas tetracycline sensitive $\left(\mathrm{Tc}^{\mathrm{s}}\right)$ strains were isolated from fusaric acid medium (Bochner et al., 1980). MacConkey medium (Miller, 1972) with $1 \%$ (w/v) mannose was used to score manA; M9 medium containing $1 \%(\mathrm{w} / \mathrm{v})$ melibiose instead of glucose was used to score melA; purA was scored on minimal medium lacking adenine, and $\mathrm{arg}^{+}$, leuB $^{+}$and $\mathrm{his}^{+}$recombinants were selected on minimal media lacking arginine, leucine and histidine, respectively. 'Dark' and 'light' colony morphology phenotypes were scored on LB plates that were incubated for approximately 1 week.

Genetic manipulations. Bacteriophage P1 transductions and $\mathrm{Hfr}$ matings were done as described by Miller (1972) and purified recombinants were scored for other markers on appropriate media. Tcs fumB-mel deletion mutants were isolated from fusaric acid medium and then scored for mel.

Plasmid pJH69 was constructed by subcloning PstI restriction fragments from pLC4-5, which carries fum $B^{+}$ (Guest et al., 1985) (Fig. 1), into the PstI site of pACYC177 (Chang \& Cohen, 1978). Plasmids pLC4-5 and pACYC177 were digested with PstI, mixed and ligated with T4 DNA ligase (New England Biolabs). 
Table 1. E. coli K12 strains

\section{Strain}

PLK1608

JH122

JH123

JH125

JH148

JH162

JH163

JH207

JH208

JH246

M2508

ES4

JH272

JH290

JH374

JH377

JH378

JH400

pLC4-5

/JA200
Relevant genotype of phenotype

$\mathrm{F}^{-}$trpR trpA9605 his-29 ilv pro-2 arg-427 thy A deoB(or $\operatorname{deoC}$ ) ts $x \lambda-\Delta 5$

$F^{-}$thr-1 leuB6 thi-1 argE3 his-4 proA2 lacY1 galK2 mtl-1 xyl-5 ara-14 rpsL31 tsx-33 $\lambda$-supE44 zdg-232::Tn10 $\Delta 5$

Hfr PO $2 \mathrm{~A}$ of Cavalli Hfr between purE and fep, transferring purE

first. relA1 tonA22 $\lambda-z d g-232:: \operatorname{Tn} 10 \Delta 5 z d j:: \operatorname{IS} 10$

Hfr PO 45 between ser $A$ and $l y s A$, transferring lysA first. thi-1 relA 1 $\lambda^{-} z d g-232:: \operatorname{Tn} 10 \Delta 5 z j d::$ IS 10

Hfr PO 1 between pyrB and pil, transferring pil first. thi-1 relA spoTI $\lambda-\sup Q 8$ zdg-232::Tn $10 \Delta 5$ zjd $:: \operatorname{IS} 10$

Hfr PO 13 between rbs and ilvE, transferring rbs first. thi-1 leu-6 gal-6

lac Yl(or lacZ4) $\lambda$ - supE44 zdg-232:: Tn10 $\Delta 5$ zjd ::IS 10

Hfr PO 18 between $\arg E$ and pur $A$, transferring $\arg E$ first. malB

$\lambda^{\mathrm{r}} \lambda-\sup E 44 z d g-232:: \operatorname{Tn} 10 \Delta 5$ zjd $:: \operatorname{IS} 10$

Hfr PO 46 between pyrE and $i l v E$, transferring ilvE first. supE 44

$\lambda^{-} z d g-232:: \operatorname{Tn} 10 \Delta 5$

JH207 with $z j d::$ IS 10

JH207 with zjd-593::Tn 10

Hfr PO2A between purE and fep transferring purE first. relAl spoTl metBl melA7

$\mathrm{F}^{-}$tonA2 lac Y(or lacZ) tsx-1 (or 70) supE44 gal-6 $\lambda$ - mtl-2 purA45 M2508 with $z d g-232:: \operatorname{Tn} 10$ and $\triangle 5$

M2508 with zjd-593:: $\operatorname{Tn} 10$ and melA $^{+}$by phage P1 transduction

JH290 with a Tn10-promoted deletion from zjd-593::Tn10-mel

JH290 with a Tn 10-promoted deletion from zjd-593::Tn10-mel

JH290 with a Tn10-promoted deletion from zjd-593::Tn10-mel

JH374 with $z d g-232:: \operatorname{Tn} 10$ and a terminus region deletion extending from manA-dgs $A$ by $\mathrm{P} 1$ transduction

pLC4-5 is from the hybrid plasmid collection of Clarke \& Carbon

(1976) and carries fumB $B^{+}$, lys $U^{+}$and cad $A^{+}$. JA200: $\mathrm{F}^{+}$thr-1 leuB6 trpE5 thi-1 recA56

* Genetic Stock Center, Yale University, Conn., USA.
Reference

or source

Henson \&

Kuempel (1985)

This study

This study

This study

This study

This study

This study

This study

This study

This study

E. coli*

E. coli*

This study

This study

This study

This study

This study

This study

E. coli*

Transformation was done as described by Dagert \& Ehrlich (1979) and recombinant plasmids were purified from kanamycin-resistant but ampicillin-sensitive clones. Purified plasmids were subjected to further restriction enzyme analysis, and a comparison of their restriction sites with the restriction map of the fumB region devised by Guest et al. (1985) allowed identification of subcloned pLC4-5 PstI fragments.

Plasmid pJH25 was constructed by digesting pLC4-5 and pACYC177 with HindIII restriction enzyme, mixing the digests, and ligating the fragments with T4 DNA ligase. Since both plasmids had only one HindIII site, pJH25 was a composite of pACYC177 and pLC4-5. Recombinant plasmid was isolated from ampicillin-resistant but kanamycin-sensitive transformants and subjected to further restriction enzyme analysis to confirm its identity.

DNA preparations. Chromosomal DNA was extracted from $100 \mathrm{ml}$ cultures by the method of Deonier \& Mirels (1977) except that the DNA was not deliberately sheared. Plasmid DNA was prepared essentially according to the Sarkosyl lysate procedure of Clewell (1972) but Triton X-100 (0.2\% final concentration) was added instead of Sarkosyl.

Restriction enzymes were purchased from New England Biolabs and used as directed. Electrophoresis of DNA was done in $0.6 \%$ submerged, horizontal agarose gels in a buffer of $80 \mathrm{mM}$-Tris/borate (pH 8.3)/1 mM-EDTA. Restriction fragments of $\lambda c 1857 S a m 7$ served as $M_{\mathrm{r}}$ standards (Daniels \& Blattner, 1982). Gels were run at $50 \mathrm{~mA}$ for 4-6 h, stained with ethidium bromide and photographed under UV light. Gels were dried on Whatman paper at room temperature and stored until their use for DNA-DNA hybridization.

Nick translation and hybridization. Thymidine $\left[\alpha^{-32} \mathrm{P}\right]$ triphosphate [approximately $3200 \mathrm{Ci} \mathrm{mmol}^{-1}$ $\left(1 \cdot 184 \times 10^{14} \mathrm{~Bq} \mathrm{mmol}^{-1}\right)$, New England Nuclear] was used to nick translate plasmid DNA according to the procedure of Rigby et al. (1977). Ethanol-precipitated, labelled plasmid DNA was resuspended in $1 \mathrm{ml}$ buffer (10 mM-Tris, $\mathrm{pH} \mathrm{7.6)} \mathrm{and} \mathrm{boiled} \mathrm{for} 10 \mathrm{~min}$ to denature the DNA; the probe contained approximately $10^{8} \mathrm{c} . \mathrm{p} . \mathrm{m}$. $(\mu \mathrm{g} \text { DNA })^{-1}$. 

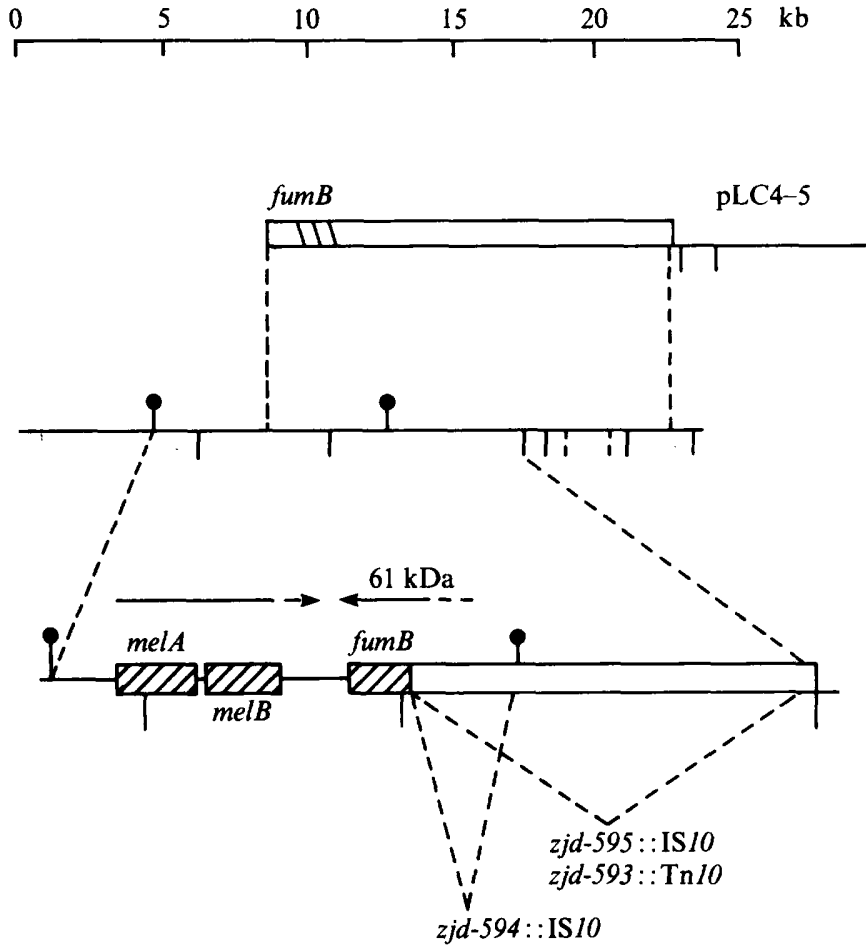

Fig. 1. Map of the fumB region of the chromosome (Guest et al., 1985) indicating positions of suppressor insertions upstream of the fumB structural gene. pLC4-5 is from the Clarke-Carbon collection of plasmids (Clarke \& Carbon, 1976). I are HindIII sites; $T$ are PstI sites.

Probe DNA was added to $50 \mathrm{ml} 5 \times \operatorname{SSC}(0.75 \mathrm{M}-\mathrm{NaCl} / 0.075 \mathrm{M}$-sodium citrate) with $50 \mathrm{mM}$-sodium phosphate buffer ( $\mathrm{pH} \mathrm{7.0)}$ and nonfat dry milk (2.5 $\mathrm{mg} \mathrm{m}^{-1}$ ) (Carnation). In DNA-DNA hybridizations on nitrocellulose filters, nonfat dry milk (BLOTTO) is a good substitute for Denhardt's ingredients (Ficoll, polyvinylpyrrolidone and bovine serum albumin) and salmon testes DNA (Johnson et al., 1984). We report here and in a preliminary communication (Makara \& Henson, 1986) that BLOTTO could also replace Denhardt's ingredients when DNADNA hybridizations were done in dried gels.

DNA in dried gels was hybridized with ${ }^{32} \mathrm{P}$-labelled plasmid DNA according to Tsao et al. (1983) with several modifications. A gel dried on Whatman paper was soaked in $0.5 \mathrm{M}-\mathrm{NaOH} / 1.5 \mathrm{M}-\mathrm{NaCl}$ in a Pyrex tray to denature the DNA in the gel. The Whatman paper was peeled from the gel when it became wet. After 15-30 min, the gel was folded and placed in a $50 \mathrm{ml}$ disposable centrifuge tube (Falcon 2098). It was briefly rinsed with $50 \mathrm{ml}$ $20 \times$ TES $(1.0 \mathrm{M}$-Trizma Base $/ 20 \mathrm{mM}-\mathrm{EDTA} / 3.0 \mathrm{M}-\mathrm{NaCl}$, brought to $\mathrm{pH} 8.0$ with $\mathrm{HCl})$ and then allowed to soak in another $50 \mathrm{ml}$ of this solution for $15-30 \mathrm{~min}$. The TES was removed and the probe solution was added. Hybridization was done in the Falcon tube at $68^{\circ} \mathrm{C}$ in a shaking water bath $(100$ r.p.m.). After $24 \mathrm{~h}$ the gel was placed in a Pyrex pan, washed twice with $5 \times$ SSC for $30 \mathrm{~min}$ at room temperature and washed three times $(1-2 \mathrm{~h}$ for each wash) in $2 \times \mathrm{SSC}$ containing $0.1 \% \mathrm{SDS}$ at $42^{\circ} \mathrm{C}$. The gel was then air dried on a 'seal-a-meal' bag, wrapped and placed on Kodak XAR-5 film with an intensifying screen at $-70^{\circ} \mathrm{C}$ for an appropriate period after which the film was developed.

\section{RESULTS AND DISCUSSION}

\section{Mutant isolation}

An unhealthy $E$. coli terminus region deletion mutant (strain PLK1608, containing $\Delta 5$ ) formed flat, transparent colonies which we called 'light' morphology (Henson \& Kuempel, 1985). After several days 'dark' papillae grew in the centre of these colonies and appeared to be growing more vigorously than the colonies from which they arose. It was possible that these 
Table 2. Interrupted matings with various Hfr strains and recipient strain JH122

\begin{tabular}{|c|c|c|}
\hline $\begin{array}{l}\text { Donor Hfr and } \\
\text { direction of transfer }\end{array}$ & $\begin{array}{l}\text { Marker } \\
\text { selected }\end{array}$ & $\begin{array}{l}\text { Percentage recombinants } \\
\text { with 'dark' phenotype }\end{array}$ \\
\hline $\begin{array}{l}\text { JH125 } \\
(\min 63 \rightarrow 62)\end{array}$ & $h i s^{+}$ & $0(0 / 100)$ \\
\hline $\begin{array}{l}\mathrm{JH} 148 \\
(\min 97 \rightarrow 98)\end{array}$ & $\operatorname{leu} B^{+}$ & $0(0 / 100)$ \\
\hline $\begin{array}{l}\mathrm{JH162} \\
(\min 85 \rightarrow 84)\end{array}$ & $h_{i s^{+}}$ & $0(0 / 74)$ \\
\hline $\begin{array}{l}\mathrm{JH} 163 \\
(\min 91 \cdot 5 \rightarrow 90)\end{array}$ & $\arg E^{+}$ & $0(0 / 100)$ \\
\hline $\begin{array}{l}\mathrm{JH} 208 \\
(\min 81 \rightarrow 82)\end{array}$ & $\arg E^{+}$ & $26(9 / 34)$ \\
\hline $\begin{array}{l}\mathrm{JH} 123 \\
(\min 13 \rightarrow 12)\end{array}$ & leuB $B^{+}$ & $8(8 / 100)$ \\
\hline
\end{tabular}

healthier derivatives of strain PLK1608 had suppressor mutations that resulted from transposition of an IS 10 because strain PLK 1608 was known to have at least one remaining IS10 in its genome (Henson \& Kuempel, 1985), and because the number of papillae which arose in each colony was consistent with the frequency of IS10 transposition (Kleckner, 1983). Also, since Tn 10 and IS 10 are capable of inactivating genes, or altering gene expression, upon transposition (reviewed by Kleckner, 1983) we speculated that the 'dark' colony phenotype could be the result of either gene activation or inactivation by IS 10 .

To test whether cells of the 'dark' colonies had a transposed IS10, chromosomal DNA was extracted from purified 'light' and 'dark' strains, digested with PstI, and hybridized with nicktranslated, ${ }^{32} \mathrm{P}$-labelled pRT16, a plasmid that carries Tn 10 (Jorgensen et al., 1979). Both 'light' and 'dark' strains had at least one PstI fragment that contained IS10, as was expected since the parental strain PLK1608 still contained an IS10. However, 'dark' strains contained an additional fragment that hybridized with the Tn 10 plasmid (G. P. Magnant and J. M. Henson, unpublished). The size $(8.0 \mathrm{~kb})$ of this new PstI fragment was identical in seven 'dark' strains that were analysed, suggesting that the 'dark' colony phenotype was the result of transposition of IS 10 , which is $1.4 \mathrm{~kb}$ in size and lacks PstI restriction sites, into a particular $6.6 \mathrm{~kb} P$ st I fragment.

\section{Preliminary mapping of the ISI0 suppressor mutation}

Mutations that suppressed any defects caused by a terminus region deletion were of particular interest since there was a possibility that they defined new genes or sites that are involved in DNA replication. The general location of the suppressor mutation was determined by interrupted mating experiments. Deletion 5 was introduced into various $\mathrm{Hfr}$ strains by phage P1 transduction and 'dark' derivatives of these deletion-mutant $\mathrm{Hfr}$ strains were isolated (Table 1). 'Dark' Hfr strains were then mated with light $\Delta 5$ recipients and the number of recombinants that displayed the 'dark' colony phenotype was scored (Table 2). Only two Hfr strains transferred the suppressor mutation relatively early. One of these, strain $\mathrm{JH} 208$, had a transfer point of origin at min 81 and transferred min 82 early, whereas the other $\mathrm{Hfr}$ (strain JH123) had a transfer point of origin at min 13 and transferred min 12 early. These two mating experiments suggested that the suppressor mutation was located between $\min 82$ and $\min 13$ on the $E$. coli map (Bachmann, 1983). Because Hfr strains JH163 and JH148 did not transfer the suppressor mutation, its location was further assigned to the region between min 92 and 97 .

\section{Isolation of a Tn10 suppressor mutation}

Unlike the dark phenotype, $\mathrm{Tc}^{\mathrm{r}}$ is a selectable and easily scored phenotype. Therefore, we next looked for a 'dark' derivative of Hfr JH207 which had a complete Tn10, encoding Tcr, inserted at the suppressor site. Strain JH207 contained $z d g-232:: \operatorname{Tn} 10(\min 36 \cdot 6)$, as well as an IS 10 associated with $\Delta 5$, and we expected that this $\mathrm{Tn} 10$ could also occasionally transpose to the 
suppressor site between min 92 and 97 to generate 'dark' derivatives of strain JH207. Of 76 'dark' derivatives of strain JH207, two transferred Tc early to a wild-type recipient and one of these (strain JH246) was chosen for further study. Strain JH246 contained a Tn10 at the suppressor site, because when it was used as the donor in a bacteriophage P1 transduction to transduce $\mathrm{Tc}^{\mathrm{r}}$ into strain PLK 1608 ('light', $\Delta 5$ ), $100 \%$ of the Tc $\mathrm{C}^{\mathrm{r}}$ transductants also had the 'dark' colony phenotype.

\section{Mapping the Tn10 suppressor mutation}

Although the suppressor $\operatorname{Tn} 10$ did not cotransduce with $\operatorname{pyr} B(\min 96 \cdot 5)$, it did cotransduce at a high frequency with melA $(\min 93.4)$; when P1 was grown on strain $\mathrm{JH} 246\left(\right.$ mel $\left.^{+} \mathrm{Tc}^{\mathrm{r}}\right)$ and used to transduce $\mathrm{Tc}^{\mathrm{r}}$ into strain $\mathrm{M} 2508\left(\right.$ melA $\left.^{\mathrm{T}} \mathrm{Tc}^{\mathrm{s}}\right), 68 \%(272 / 400)$ of the $\mathrm{Tc}^{\mathrm{r}}$ transductants were $\mathrm{melA}^{+}$. The suppressor Tn 10 also cotransduced at a detectable rate with purA (min 95). Again P1 was grown on strain $\mathrm{JH} 246\left(p u r A^{+} \mathrm{Tc}^{\mathrm{r}}\right) ; 21.5 \%(86 / 400)$ of the $\mathrm{Tc}^{\mathrm{r}}$ transductants of recipient strain ES4 (purA $\mathrm{Tc}^{\mathrm{s}}$ ) were also pur $A^{+}$. Some transductants were probably $\mathrm{Tc}^{\mathrm{r}}$ because of transduction of $z d g-232:: \operatorname{Tn} 10$ instead of the suppressor $\operatorname{Tn} 10$ from the donor, although $z d g$ $232:: \mathrm{Tn} 10$ transduces at low frequency because of its close proximity to $\Delta 5$ in strain $\mathrm{JH} 246$. Hence, cotransduction of the suppressor $\operatorname{Tn} 10$ with melA and purA was probably higher than $68 \%$ and $21.5 \%$, respectively. Because these transduction data placed the suppressor $\operatorname{Tn} 10$ very near melA, between min 93 and 94, it was designated $z j d-593:: \operatorname{Tn} 10$.

Guest and co-workers (Guest \& Roberts, 1983; Guest et al., 1985) recently identified and mapped fumB, a gene that allows growth of a fum $A l$ point mutant on fumarate minimal medium when present in high copy. They also found that $f u m B$ was closely linked to melA, constructed a restriction map of several plasmids which carry the $m e l A-$ fum $B$ region of the chromosome and determined the direction of transcription of the fumB gene. fum $A l$ mutants are unable to grow aerobically on fumarate or acetate, but fumB $B^{+}$, if present in high copy, such as on a ColEl-fumB $B^{+}$ plasmid, allows growth of fumAl mutants on fumarate minimal medium.

The fum $A$ gene is located in the terminus region of the chromosome and is deleted from strain PLK 1608. Because of the close proximity of fumB to melA, it seemed possible that $z j d$ $593:: \mathrm{Tn} 10$ was located upstream of the $f u m B$ structural gene and caused an increased expression of this gene. A finding that supported this possibility was that 'dark' strains grew on minimal fumarate medium, whereas 'light' strains did not. A relatively strong promoter ( $p$-OUT) is present on IS 10 and Tn 10 and capable of directing transcription of adjacent chromosomal DNA (Kleckner, 1983).

To determine if $z j d-593:: \mathrm{Tn} 10$ was located near the promoter region of the fumB gene, DNADNA hybridization experiments were conducted with nick-translated pLC4-5 ( $\left.\mathrm{fumB}^{+}\right)$and chromosomal restriction fragments from several insertion mutants and a wild-type strain (Fig. 2). Parental strain M2508 (Fig. 2a, lane 1) had two PstI fragments, approximately 4.6 and $6.6 \mathrm{~kb}$, that hybridized with pLC4-5. Smaller PstI fragments that hybridized with pLC4-5 were cut from the photograph of the autoradiogram in Fig. 2. In 'dark' strains that had $z j d-593:: \operatorname{Tn} 10$ (Fig. 2a, lanes 2-4), the $6.6 \mathrm{~kb}$ Pst I fragment was missing and a $16 \mathrm{~kb}$ fragment appeared, as would be expected if $\mathrm{Tn} 10$ (which is $9.6 \mathrm{~kb}$ and contains no Pst I sites) inserted into the $6.6 \mathrm{~kb}$ PstI fragment. In strains that had an IS 10 insertion (Fig. $2 a$, lanes 6 and 7) the $6.6 \mathrm{~kb}$ fragment is missing and an $8.0 \mathrm{~kb}$ band appears, as would also be expected if IS 10 inserted into the $6.6 \mathrm{~kb}$ fragment. Of 16 insertion mutants tested by hybridization, all 16 had an insertion in the $6.6 \mathrm{~kb}$ Pst fragment just upstream of the fumB structural gene (kb 11-17 on Guest's map of the fumB region) (Fig. 1). Chromosomal DNA from strain M2508 and various insertion strains was also digested with HindIII and hybridized with pLC4-5 (Fig. $2 b$ ). M2508 had a high- $M_{\mathrm{r}}$ fragment and an $8.0 \mathrm{~kb}$ HindIII fragment that hybridized with labelled probe (Fig. 2b, lane 1). Most insertion strains had a HindIII pattern that looked identical to the parental strain (Fig. $2 b$, lanes 2 and 3). This would be expected if their insertions were in the large HindIII fragment; high- $M_{\mathrm{r}}$ fragments with IS 10 insertions would not be resolved from the high- $M_{\mathrm{r}}$ wild-type fragment with electrophoresis conditions used in this study. An occasional IS10 insertion strain, however, was missing the $8.0 \mathrm{~kb}$ HindIII fragment and a $9.5 \mathrm{~kb}$ band appeared instead (Fig. 2b, lane 4). These results indicated that although all insertions occurred in the 11-17 kb PstI fragment, they could 
(a)

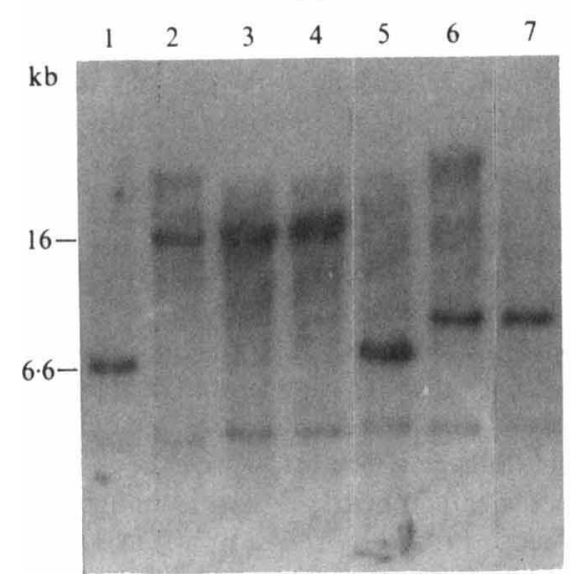

(b)

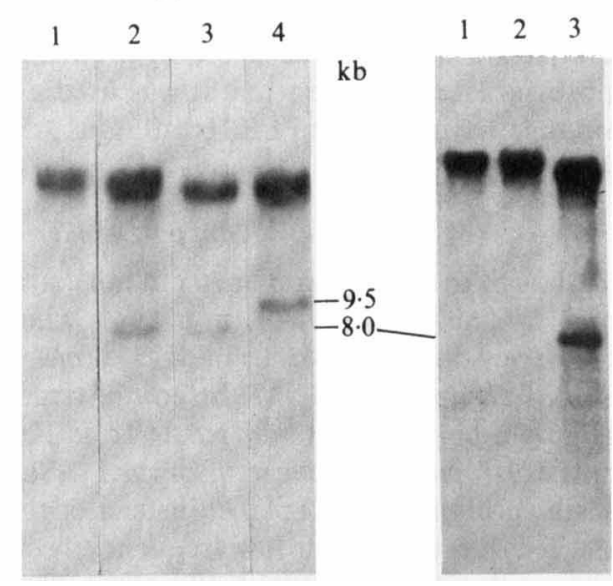

Fig. 2. Autoradiogram of a $0 \cdot 6 \%$ agarose gel of DNA that was hybridized with ${ }^{32} \mathrm{P}$-labelled pLC4-5. (a) Chromosomal DNA from various strains digested with $P$ st I : lane 1, DNA from strain M2508; lanes 24, DNA from several strains with $z j d-593$; lane 5, DNA from strain JH272 (M2508 with $z d g-232:: \operatorname{Tn} 10$ and 45 ); lanes 6 and 7, DNA from two strains that have zjd::IS10. (b) Chromosomal DNA digested with HindIII : lane 1, chromosomal DNA from M2508; lanes 2 and 3, chromosomal DNA from strains with $z j d-595::$ IS 10 ; lane 4, chromosomal DNA from a strain with $z j d-594::$ IS 10 . (c) Chromosomal DNA from two zjd-593:: Tn 10-mel deletion strains (JH377, JH378) and a wild-type strain digested with HindIII and hybridized with pLC4-5.

occur on either side of the HindIII site located at kb 12.5 on Guest's map of the fumB region. One IS 10 , located to the left of the HindIII site at kb 12.5, was designated zjd-594::IS10, whereas another IS 10 on the right of the HindIII site was called $z j d-595::$ IS 10 . Because $z j d-594::$ IS 10 was in the 11-17 kb PstI fragment and the 4-12 kb HindIII fragment, its location could be narrowed to within $\mathrm{kb} 11-12$. Guest et al. (1985) (J. R. Guest, personal communication) predicted that the $f u m B$ structural gene starts at $\mathrm{kb} 11.5 \pm 0.2 \mathrm{~kb}$. This would place $z j d-594::$ IS 10 immediately upstream of fumB. Since $z j d-595::$ IS 10 was to the right of the HindIII site at $12.5 \mathrm{~kb}$ but still within the $11-17 \mathrm{~kb}$ Pst fragment, it was situated between $\mathrm{kb} 12.5$ and $17 \mathrm{~kb}$ on the fumB region map.

The exact location of $z j d-593:: \operatorname{Tn} 10$ could not be discerned from our hybridization experiments. Strain JH290 had HindIII fragments of the same size as its parental strain M2508; however, because Tn 10 has two HindIII sites, the Tn 10 could have been located on either side of the $\mathrm{kb} 12.5$ HindIII site and given this result. The Tn 10 was within $2 \mathrm{~kb}$ of the HindIII site; if it was at a greater distance, new HindIII fragments of sufficient size to be detected by hybridization would have been generated.

\section{Construction of fumB deletion mutants}

Since there are no known fumB mutants, we used $z j d-593:: \operatorname{Tn} 10$ to construct fumB-mel deletions. Tn10 is known to promote deletions of adjacent DNA (Kleckner, 1983) and $\mathrm{Tc}^{\mathrm{s}}$ deletion mutants can be isolated on fusaric acid medium (Bochner $e$ t al., 1980). $\mathrm{Tc}^{\mathrm{S}}$ derivatives of strain JH290 were screened for $\mathrm{Mel}^{-}$; since $\mathrm{fumB}$ lies between the mel operon and $z d g-593:: \operatorname{Tn} 10$, it was assumed to be deleted in these strains. Subsequent hybridization experiments with pLC4-5 demonstrated that all of these deletions were missing the fumB PstI restriction fragment and all of the DNA on the HindIII fragment from kb 4-12.5 that shares homology with pLC4-5 (Fig. 2c). Since IS10 is also notorious for causing inversions, as well as deletions of adjacent DNA (Kleckner, 1983), we also did a hybridization experiment with pLC4-5 and deletion strain chromosomal DNA doubly digested with PstI and EcoRI. All eight 
deletion strains were missing the PstI/EcoRI fragment from kb 9-11 (data not shown). This fragment would have been present in any strains that had an inversion of DNA from zjd-593::Tn 10-mel instead of a deletion of that DNA.

All eight deletion strains grew well aerobically in fumarate minimal or rich media, which demonstrated that the fumB gene is not essential for growth under these conditions.

\section{Complementation studies with $p L C 4-5$ subcloned fragments}

Although it seemed likely that $\mathrm{Tn} 10$ was providing a relatively strong promoter for increased expression of $f u m B$, it was also possible that $z j d-593:: \operatorname{Tn} 10$ was inactivating a gene whose product represses fumB. Therefore, we subcloned the PstI fragment from kb 11-17 into the PstI site of pACYC177 (Chang \& Cohen, 1978) and transformed 'dark' strains with the recombinant plasmid pJH69. If the subcloned fragment encoded a repressor of fumB, one might expect that the phenotype of transformed 'dark' strains would turn to 'light' and they would be unable to grow on fumarate. However, 'dark' strains remained 'dark' and grew on fumarate minimal medium. We also did complementation tests with plasmid pJH25 which is a composite plasmid of pLC4-5 and pACYC177. If pLC4-5 has a fumB repressor gene, it must span the HindIII site in the plasmid because it can be inactivated on either side of this site. We reasoned that if pLC4-5 was cut with HindIII and subcloned into the HindIII site of pACYC177, then the putative repressor gene would be inactivated and $\triangle$ fum $A C \triangle$ fumB strains transformed with this hybrid plasmid would grow faster on minimal fumarate medium than $\triangle$ fum $A C \triangle$ fumB mutants that were transformed with pLC4-5 (with an intact putative fum $B$ repressor gene). A mutant deleted for fum $A C$ and $f u m B$, strain $\mathrm{JH} 400$, was constructed by transducing $\triangle 5$ into strain $\mathrm{JH} 374$ $(\triangle$ fumB $)$. The mutant transformed with $\mathrm{pJH} 25$ did not grow faster on fumarate than the mutant transformed with pLC4-5 (data not shown).

Guest et al. (1985) suggested that fumA and fumB, which share homology, may act as positive regulatory elements for fum $C$, which in turn would encode a fumarase that catalyses the interconversion of fumarate and L-malate in the TCA cycle. However, growth can occur on minimal fumarate in the absence of fum $C$ and fum $A$ which suggests that $f u m B$ encodes a fumarase instead of a positively regulating factor acting on fum $C$. Recent experiments done by S. A. Woods and J. R. Guest demonstrated that fum $A$ and fum $C$ encode independent fumarases (J. R. Guest, personal communication). Because fumB and fum $A$ share homology, fumB would also presumably encode a fumarase. Perhaps $f u m B$ is a poorly expressed vestigial fumA gene, as suggested by Guest et al. (1985).

The Fum ${ }^{-}$phenotype of smaller fumAC deletions was also suppressed by $z j d::$ IS 10 or Tn 10 insertions. However, the insertions did not suppress other abnormal phenotypic properties of large terminus region deletion strains; for example, 'dark' derivatives of strain PLK1608 still formed many filamentous cells. Although other possibilities exist, it was likely that $\operatorname{Tn} 10$ or IS 10 insertions 1-3 kb upstream of the fumB structural gene suppressed the Fum- phenotype of terminus region deletion strains by providing a stronger promoter for greater expression of fumB.

We thank Drs B. Bachmann, J. R. Guest and P. K. Kuempel for strains and helpful discussion. We especially thank Dr Guest for communicating his results prior to publication. This work was funded by MONTS, and grant DMB-8507753 from the National Science Foundation.

\section{REFERENCES}

BachmanN, B. J. (1983). Linkage map of Escherichia coli K-12, edition 7. Microbiological Reviews 47, 180-230.

Bochner, B. R., Huang, H. C., Schieven, G. L. \& AMEs, B. N. (1980). Positive selection for loss of tetracycline resistance. Journal of Bacteriology 143, 926-933.

Chang, A. C. Y. \& Cohen, S. N. (1978). Construction and characterization of amplifiable multicopy DNA cloning vehicles derived from the P15A cryptic miniplasmid. Journal of Bacteriology 134, 11411150.

Clarke, L. \& Carbon, J. (1976). A colony bank containing synthetic ColEl hybrid plasmids representative of the entire Escherichia coli genome. Cell 9, 91-99. 
Clewell, D. B. (1972). Nature of ColE1 plasmid replication in Escherichia coli in the presence of chloramphenicol. Journal of Bacteriology 110, 667-676.

Dagert, M. \& EhrLICH, S. D. (1979). Prolonged incubation in calcium chloride improves the competence of Escherichia coli cells. Gene 6, 23-28.

DANiels, D. \& Blattner, F. (1982). Nucleotide sequence of the $Q$ gene and $Q$ to $S$ intergenic region of bacteriophage $\lambda$. Virology 117, 81-92.

DeONIER, R. C. \& Mirels, L. (1977). Excision of F plasmid sequences by recombination of directly repeated insertion sequence 2 elements. Proceedings of the National Academy of Sciences of the United States of America 74, 3965-3969.

Guest, J. R. \& RoberTs, R. E. (1983). Cloning, mapping and expression of the fumarase gene of Escherichia coli K12. Journal of Bacteriology 153, 588-596.

Guest, J. R., Miles, J. S., Roberts, R. E. \& Woods, S. A. (1985). The fumarase genes of Escherichia coli: location of the fumB gene and discovery of a new gene (fumC). Journal of General Microbiology 131, 2971-2984.

Henson, J. M. \& Kuempel, P. L. (1985). Deletion of the terminus region ( 340 kilobase pairs of DNA) from the chromosome of Escherichia coli. Proceedings of the National Academy of Sciences of the United States of America 82, 3766-3770.

Johnson, D. A., Gautsch, J. W., Sportsman, J. R. \& ELDER, J. H. (1984). Improved technique utilizing nonfat dry milk for analysis of proteins and nucleic acids transferred to nitrocellulose. Gene Analytical Techniques 1, 3-8.

JORGENSEN, R. A., BERG, D., Allet, B. \& REZNIKOFF, W. S. (1979). Restriction enzyme cleavage map of Tn10, a transposon which encodes tetracycline resistance. Journal of Bacteriology 237, 681-685.

KLECKNeR, N. (1983). Transposon Tn10. In Mobile Genetic Elements, pp. 261-298. Edited by J. A. Shapiro. Orlando, Florida: Academic Press.

Makara, M. P. \& Henson, J. M. (1986). BLOTTO for dried agarose gels. In Focus, vol. 8, pp. 14-15. Bethesda, Maryland, USA: Bethesda Research Laboratories.

MilleR, J. H. (1972). Experiments in Molecular Genetics. Cold Spring Harbor, New York: Cold Spring Harbor Laboratory.

Tsao, S., Brunk, C. \& Pearlman, R. (1983). Hybridization of nucleic acids directly in agarose gels. Analytical Biochemistry 131, 365-372. 